\title{
GLOBALISATION AND THE LABOUR MARKET
}

\author{
Brian Easton \\ Economic and Social Trust \\ On New Zealand
}

\begin{abstract}
This paper explores the consequences of globalisation for the labour markets. By defining globalisation as 'the consequence of the diminishing costs of distance the analysis is able to use the economist's standard trade theory to show explore the impact of globalisation on labour mobility in the impact of trade of labour conditions, and of differential mobility (the favouring of skilled migrants over unskilled migrants). Some consideration is given to the particular circumstances of the New Zealand labour market. One conclusion of this - all to brief - paper is to insist that migration must be seen in the context of a particular sort of globalisation of the labour market.
\end{abstract}

\section{Introduction $^{1}$}

It is argued that globalisation was a far more potent force in the nineteenth century, than it has been in the late twentieth, for then labour was highly mobile as well as capital and goods - although it was really only European labour which was mobile. Moreover, aside from initiative, the labour which migrated probably had similar characteristics to those which stayed behind. ${ }^{2}$

In contrast, today there are restrictions on labour mobility, which tend to favour the skilled and the rich. However, such international labour mobility there is, is no longer confined to Europeans and their descendants. Indeed in some respects Europeans are today more satisfied with their lot, and are less inclined to migrate outside the continent, so the greatest pressures come from inhabitants of second and third world economies. It would be wrong to assume that there is an international labour market (except in a very few select occupations) but it would be equally wrong to assume that labour was fixed in location, as is usually postulated in standard international trade models.

The result is that we rarely have a clear vision of the international labour market, and the policy responses tend to be ad hoc - as in the case of the current debate about immigrants. This paper tentatively explores some of the issues.

\footnotetext{
${ }^{1}$ I am grateful for some useful comments on an earlier version of this paper from Bill Rosenberg.

${ }^{2}$ K.H. O'Rourke \& J.G. Williamson (1999) Globalisation and History: The Evolution of a Ninteenth-Century Atlantic Economy, MIT.
}

\section{Globalisation}

My work uses the definition of globalisation as 'the consequences of reductions in the cost of distance'. It argues that even if geographical distances have not changed, distance has effectively diminished because the time involved, the resources used, and the insecurity of travel and transport have all reduced. However the diminution differs by that which is travelling. While the reductions for goods shipped by sea have been dramatic, they are small in comparison to the reductions for people and goods which were once shipped by sea and now fly, while the reduction in the costs and times of moving information are such that the effective distance is near zero.

The previous sentence is from a perspective of New Zealand in the world. A more comprehensive account would mention the spectacular reductions that have occurred from railways in the nineteenth century and road transport in the twentieth. Their impact on the development of North America and Europe has been enormous, and even the regional economic structure of a country as tiny as New Zealand is undergoing changes as the costs of land transport diminish. However the focus in this paper is the international dimension. A central feature of this approach is that many of the difficulties on globalisation arise from the fact that different costs of distances diminish at different rates.

\footnotetext{
${ }^{3}$ e.g. B. H. Easton, (2002) Towards An Analytic Framework for Globalisation, publication pending, on website www.eastonbh.ac.nz.
} 
The diminishing costs of distance impacts on labour markets in a variety of ways. Most obviously it changes the relative costs of home and foreign supply, favouring the latter. A particular case is where there are strong economies of scale in the production process, so that even if the two countries have identical endowment shares and available technologies, industry in the larger country will expand at the expense of the smaller country. Transport costs are natural protection and the consequence of their reduction is a diminution in that protection. Probably this effect is far more important today than the reductions in tariff and other government protections, and arguably latter is a consequence of the former.

\section{The Relevance of Trade Theory}

One merit of treating transport costs as natural protection is that the standard trade models can be used to analyses the effects of the change, although the models have to be used in full rather than in their partial form which look only at the difference between an international trading regime with tariffs and one without. Moreover such phenomenon as economies of scale and technological change are integral and should not be omitted from the model as they tend to be at the elementary level.

In particular, product specialisation and economies of scale generate intra-industry trade, that is trade in both directions between two countries in broadly the same product (so Germans buy Renaults and Frenchmen buy Volkswagens). This does not seem to markedly change the anaylsis of labour markets under globalisation, although it changes dramatically our understanding of what is, and can be, traded. However further investigation may suggest some interesting propositions - especially about the significance of skills.

Despite it being one of the driving forces behind the antiglobalisation movement, one issue which this paper does not pay a lot of attention to is that any increasing of international trade will result in the redeployment of factors (including labour) from some industries to others. Typically this redeployment will involve some unemployment and - often severe - social adjustment by the those involved. It is even possible that some factors will never be redeployed. While not wanting to minimise the distress, or the concerns of those who protest against policies which exacerbate this adjustment, the focus of this paper is where long term adjustment has occurred, and factors are fully redeployed. This provides some insights, not all of which are as favourable to globalisation as its advocates claim.

\section{Globalisation with Immobile Labour}

To begin with the standard assumption that only goods travel and that capital and labour are fixed in each economy. A reduction in protection (while the model looks at tariffs, but it also broadly applies for transport costs), which increases trade between two countries, will generally favour the factors which are used more intensively in the industries which expand and disadvantage those more intensively deployed in the industries which contract. One of the main focusses of this scenario is the shift of manufacturing from first to third world economies, with the implication that there will be a relative reduction in wages in the first world manufacturing industries which are competing with the third world.

In its extreme form this 'factor price equalisation' does not seem to apply, but presumably there is a tendency. In particular the theory suggests that products from third world countries based on their abundance of unskilled labour will undercut the domestically produced equivalents, and press down on the wages of the unskilled in the first world. As a result there will be a tendency for the margins for skill to open up in the first world (and to close in the third world).

In effect this trade exports unskilled labour from the third world to the first world by embodying it in traded goods. For instance, India - among others - can provide call centre workers at lower cost than New Zealand can. We might imagine Indians flying to New Zealand each day, working in the call centre, and then flying home, with no other impact on New Zealand society. Travel costs aside, the effect would be to reduce the wage rates of local call centre operators, and decrease their wages relative to other New Zealand workers which the Indians cannot displace. In fact, the travelling is unnecessary because exceptionally cheap international telecommunications means the call operators can work at home and yet supply (export) the service to New Zealand. So the impact on potential local call operators is the same as if the Indians were working in New Zealand.

There is evidence that margins for skill have increased in the first world in the last three decades. But it is not clear that this is due to increasing trade. Many experts attribute the increase to technical change which tends to favour skilled workers. For instance, it seems likely that new technologies displace unskilled workers and/or create opportunities for skilled workers or for skills that did not previously exist. However this is not a unanimous conclusion, and even these experts acknowledge that there is probably some effect on margins for skill from the globalisation of production. ${ }^{4}$

Moreover, whatever may have been happening in the past, it is not impossible that the globalisation effect will intensify in the future as distance costs come down, protection is reduced, and particularly, China increases its role in the world market. However it is not clear what

4 P.R. Krugman \& M. Obstefeld (2000) International Economics: Theory and Policy, Addison-Wesley, 5th ed, p.7981. For a view which gives more weight to the impact of trade on the income distribution see D. Baker \& M. Weisbrot (2001) Will New Trade Gains Make Us Rich? An Assessment of the Prospective Gains from New Trade Agreements, Centre for Economic and Policy Research, Washington. 
range of goods and services or component processes the phenomenon will apply to. We may not be surprised that all underwear production has moved offshore, but first world fashionware may survive because of the demands of niche markets, the needs of design closely integrated with the production process, and the requirement for high-skilled quality-controlled products. Obviously there are a few vulnerable industries remaining in New Zealand (most notably textile, clothing and footwear, where border protection is still moderately significant), but the bigger threat from third world exporters may be to New Zealand's Australian markets as its tariffs and distance costs of suppliers are reduced.

One policy response to the loss of unskilled jobs from globalisation is to systematically upskill (and redeploy) the labour force. Given that the increasing margins for skill is not solely due to international trade, but that new technologies seem even more important, one might conclude that there is a strong case for the upskilling/redeployment strategy.

What to do about the margins for skill? Generally economists are cautious about policies which try to squeeze the margins in wage rates because that may make those goods and services most dependent upon unskilled labour less competitive to overseas producers. Moreover, as the next section discusses, skilled labour is internationally mobile, and to some extent pay influences where it settles. Squeezing skilled wages encourages emigration (and the failure to return).

\section{Globalisation with (Skilled) Migration}

Thus far we have assumed that the labour is confined to a particular economy. While migration flows may not be as relatively great as they were in the nineteenth century, they remain substantial. As the introduction noted, the difference is that the mobility no longer applies to unskilled Europeans. Today the mobile - to a greater or lesser degree - are suitably skilled workers of all races. (There is some mobility of the lesser skilled as refugees and illegal immigrants.) Even so, the size of the likely flows are such that in the long run there is likely to be substantial geographical change in the patterns of employment.

Because this paper concentrates on the labour market, it assumes that capital and technology are reasonably (although probably not perfectly) mobile. (The assumption could have been made in the previous section without loss of the general conclusions, although it would change the transition paths and timing.) What is explored here is the impact of migration of skilled rather than unskilled workers.

It is argued that the nineteenth century migration benefited workers in the country of origin because it reduced the number of workers on the land. ${ }^{5}$ The explicit assumption here is that there was diminishing returns to land on which the workers farmed: the implicit assumption is labour was homogeneous. Today's migrants do not generally come from farms (although there may be a chain reaction in which the urban based unskilled migrants of the third world leave positions for farm workers to take over), and they are not representative of the labour markets they leave.

It is generally assumed that all migrants are better off because they chose to migrate, although there are obviously some caveats here such as they may have been misinformed and unable to return. The situation of workers in the destination country is more complicated, since there will be a tendency of the immigrants to push their wages down. However if there are economies of scale or if the skills the immigrants bring are complements to the domestic workers skills the wage pressure may be offset by productivity gains. The implications for the domestic sector are very situation specific, as they are also for source country. So we need to explore a relevant example.

Consider a particular labour skill migrating, say, from New Zealand to Europe, because its factor return is higher in Europe than New Zealand. Because they have chosen to move, the New Zealanders with the skills are better off, while those already in Europe with the same skills will experience lower wages from the additional supply and be worse off. (This assumes that economies of scale are not important.) But what about the rest of those involved?

The migration of labour, capital/savings and technology are all facilitated by the falling costs of distance. There is a tendency to assume that such migration is necessarily a good thing, but it is not always clear what are the assumptions that are being used to justify the conclusion. Typically the analysis ignores the distributional impact of the change. Even if both the source or destination economy are better off in the sense that per capita output is higher, there may be people who are worse off.

Curiously, and not in line with what is generally assumed, the unskilled need not be necessarily worse off from skilled immigration. For instance if there is complementarity in the production process between the skills and the unskilled (and assuming some capital mobility) an immigrant inflow may create opportuinities for the local unskilled. But such is the complexity of the issue even this conclusion is subject to the caveat, that the unskilled may have been even better off had some of them been upskilled, rather than sourcing the skills from overseas (assuming that domestic upskilling is possible).

\section{The Globalisation of the Labour Market}

To summarise, the global labour market is likely to continue to have strong barriers to the mobility of most especially unskilled - labour, although there will be 
substantial movements of world population in the long run.

International trade is a means of generating some of the outcomes which have some analogies to greater international mobility of labour. In particular it should depress the remuneration of unskilled labour in rich countries (as would an inflow of unskilled labour from poor countries). However, the magnitude of this effect seems small (and the increasing margins for skill in rich countries can be attributed more to biases in technological innovation). It is possible the effect will accelerate with further reductions in the cost of distance and China (in particular) becoming a more dominant exporter of general manufactures.

Skilled labour is likely to be increasingly mobile, and this will be largely independent of the ethnicity - or other cultural attributes - of those workers. The impact of the workers in the destination (or source) country is not clear, because different circumstances have quite different outcomes.

\section{The Implications for New Zealand}

The globalisation of the (skilled) labour market has two implications for New Zealand. The first, about emigration, is that many New Zealanders are going to be welcome in other rich countries, and they will afford themselves of the opportunity to take up the invitation for many it will be permanently or for a long period. Some of the policy issues which come out of this paper are:

1. To what extent is the acquisition of New Zealander's mobile skills to be funded by the state or by the individual, given that the beneficiary country may not always be New Zealand?

2. What steps should New Zealand take to attract its expatriates back to New Zealand? The question assumes that $\mathrm{OE}$ will be a major - and increasing - element in the experience of New Zealanders.

3. Is it possible to harness New Zealand expatriates in the interests of New Zealand? (An interesting attempt to do this is the Kiwi Expatriate Association - KEA - which tries to create connections which involve expatriates in New Zealand projects.)

The second group of questions involve the offsetting immigration. While some immigrants will be of refugees and for family reunion, an important component will be skilled labour and also immigrants with capital. among the policy questions that have to be worked through are:

4. What is the purpose of this immigration? Note that it will not contribute greatly to increasing New Zealand's population size. An extra 5000 immigrants a year (net) adds about 350,000 to the population over a 50 year period (including from the births to migrants), an additional .15 percent p.a. to the rate of population growth. Nor does it seem likely that the aging of the population can be delayed significantly by any likely migration flow. (A related issue is what is the maximum rate which the economy and society to absorb immigrants, without putting excessive pressure on New Zealand.)

5. Suppose the purpose is a part of skills enhancement. If migration policy is (largely) a skills enhancement strategy, should it not be integrated with a strategy which currently hardly exists - to upskill the New Zealand population?

6. Insofar as part of the immigration policy is to bring investors (entrepreneurs belong to the skills strategy) to New Zealand, how effective are they, and what advantages does the strategy have - if any - over simply recruiting the capital without giving residential rights to the investors?

These six questions are not comprehensive and they omit migration issues which are not strictly labour market ones, such as this which involve refugees and family reunions.

In regard to the cultural questions, it should be noted that some 19.5 percent of New Zealand residents in 2001 were born overseas. Out of the 18 OECD countries for which data is available, only Australia at 24 percent has a higher proportion and only Canada, Sweden, and the United States exceed 10 percent. It is inevitable that immigrants will be culturally different from the existing population, and there is an issue of the ability of New Zealand's absorption rate (culturally and economically). Undoubtedly the culture and vitality that migrants bring with them can contribute to a dynamic society. However it is possible to exaggerate this - often for quasi-racist reasons. For instance Asian migrants contribute to the transformation of New Zealand, but the economic forces of globalisation and the penetration of overseas ideas and fashions, together with the internal dynamic of New Zealand society are far more important in the transformation than any Asianisation. There is a danger we may attribute to Asian immigrants all the uncomfortable aspects of the transformation, even when they were caused by other processes, and ignore the Asian contribution to the positive aspects of the transformation.

Taking on a partial perspective to an issue while ignoring the wider context is not peculiar to cultural aspects migration. Indeed one point of this - all to brief - paper is to insist that migration must be seen in the context of a particular sort of globalisation of the labour market. 